\title{
The Foreign Students' Communicative Competence Development in the Tatar Language
}

\author{
${ }^{* 1}$ Rashat N. Yakupov, ${ }^{2}$ Kadriya S. Fatkhullova, ${ }^{3}$ Elvira N. Denmukhametova, ${ }^{4}$ Kuandik S. Kulmanov \\ 1, 2, 3 Kazan Federal University, Leo Tolstoy Institute of Philology and Intercultural Communication, ${ }^{4}$ L.N. Gumilev \\ Eurasian National University (Kazakhstan, Astana) \\ "Email: elvir25@mail.ru<mailto:elvir25@mail.ru>: contact: 89196854180
}

\section{Received: 21st October 2017 Accepted: 16th November 2017, Published: 31st December 2017}

\begin{abstract}
Article is devoted to a problem of foreign students' communicative competence development in Tatar receiving higher education in KFU and according to curricula learning Tatar in a certain volume. In recent years the teachers of IFMK of L. Tolstoy developed manuals for new generation foreign students' training in Tatar on the basis of system and activity approach and having a communicative focus. Thanks to them students have an opportunity practically to master Tatar as means of interpersonal and cross-cultural communication. Relevance of this article is explained by these factors. Article lights methodical system of speech development, language and sociocultural competences of students in main types of speech activity in the course of studying Tatar. When developing manuals for teaching Tatar to foreign students' authors relied on long-term experience in this direction, on innovation in the field of training in foreign languages, modern achievements of linguodidactics. Approbation of the developed tutorials is carried out when training students at various institutes of KFU, as well as on Tatar courses in which the representatives of the different countries who arrived to the Republic of Tatarstan to study or work study. Introduction in practice of training in Tatar of the manuals developed by authors promotes improvement of communicative abilities of foreign students, realization of the set educational objects.
\end{abstract}

Keywords: System and Activity Approach, Communicative Competence, Training in Tatar, Foreign Students, Tutorials, KFU.

\section{Introduction}

Among many languages having ancient historical roots in the person of written monuments also Turkic languages among which worthy place is taken also by the modern Tatar literary language which is by quantity speaking this language the second language after Russian in the Russian Federation remain. In the last decades Tatar as a state language of RT is one of subjects at institutes of the Kazan federal university.
For improvement of language education in modern conditions it is necessary to lift to qualitatively new methodical level teaching Tatar as nonnative and to introduce modern tutorials in practice of training; to constantly increase the social importance of Tatar. One of activities of department of general linguistics and Turk Study of Institute of philology and cross-cultural communication of $\mathrm{L}$. Tolstoy of $\mathrm{KFU}$ is training in Tatar of the foreign citizens coming to our higher education institution on training within programs of the academic mobility as well as the students studying in the different directions of preparation. First who became interested in studying Tatar in the Kazan University were our German colleagues from Institute of a Turk Study of Free university of Berlin. In the next years representatives of the USA, Japan, Korea, Finland, Japan, Holland, France and other countries showed interest in studying Tatar. The geography of the citizens learning Tatar extends every year.

Research objective - is to develop and introduce in practice of training in Tatar of foreign students of the tutorial of new type according to the set educational purposes, aimed at the communicative competence development of students. In scientific research various aspects of training in Tatar as nonnative were considered, but the problem of foreign students' communicative competence development in Tatar was not object of special studying.

\section{Materials and Methods}

For carrying out this research we studied innovations in a technique of training in foreign languages; modern educational technologies. When developing manuals for training in Tatar of Russian-speaking and foreign students the authors relied on long-term practical pedagogical experience in this direction; achievements of linguo-didactics. Today trilingual manuals for learning Tatar (in the Tatar, Russian and English languages) are created by "Let's speak Tatar" [Fatkhullova K. S. ... 2012]; bilingual grants "Tatar for beginners. Intensive course" [Shayakhmetova L. H., 2012]; "We speak, we read, we write in Tatar" 
[Fatkhullov K. S. ... 2015]; "Technology of training in Tatar on the basis of speech models" [Maximov N. V., 2015]. Approbation of the developed tutorials is carried out when training students at various institutes of KFU, when holding individual occupations with foreign trainees, as well as on Tatar courses for a general population in which also the representatives of the different countries who arrived to the republic for study or for work study.

When carrying out this research the following methods were used: method of the theoretical analysis, comparative method, statistical method and method of generalization.

\section{Results}

The main components of communicative competence are: 1) speech, 2) linguistic, 3) social and linguistic, 4) discourse, 5) strategic, 6) sociocultural. Knowledge of Tatar as the means of communication includes knowledge of language material, development of skills of speech communication, as well as ethno cultural abilities. In this regard opredelenysovremenny methodical approaches for foreign students' communicative competence development in Tatar which allow to form necessary abilities on main types of speech activity (audition, speaking, reading, the letter). For this purpose the manuals developed by us included various tasks and types of exercises.

\section{Discussion}

Language receives the practical embodiment only in the speech and through it carries out the communicative appointment therefore knowledge of Tatar as the means of communication provides implementation of vigorous speech activity. As shows experience of teaching Tatar to foreign students, it is impossible to teach them to speech communication, without having created communicative skills of speech activity. As it is emphasized in methodical literature, communicative competence is an ability to understand and generate the statement in the learned language taking into account the purposes, time, places and situations of communication [Fahrutdinova R.A., 2014., rp. 36-46; Karabulatova, I.S, 2013., pp.141-145; Yakupov R., 2016, ss. 221-226; Nagimov N.I., 2015. SS. 411-415; Kharisov F.F., 2014, ss. 4439-443; Konopatskaya E., 2015, ss. 2306-2310]. The solution of this task caused creation of tutorials taking into account basic provisions of system and activity approach. When developing the manual "Let's speak Tatar" for authors the linguo-methodological system directed to practical mastering main types of speech activity - audition, speaking, reading, the letter was initial. The subjects for development of the coherent speech and reading individual correctic
2183
Copyright (C) 2018 Helix ISSN 2319-5592 (Online) development of the coherent speech and reading individual correctic
2183
Copyright (C) 2018 Helix ISSN 2319-5592 (Online) development of the coherent speech and reading
2183
Copyright (C) 2018 Helix ISSN 2319-5592 (Online) presented in the textbook were chosen taking into account informative and communicative interests of foreign students and directed to informing them about features of etiquette, national traditions, culture and art, outstanding persons of the Tatar people. The textbook is made taking into account such methodical provisions of a communicative technique. The main contents of this textbook are aimed at the development and improvement in students of skills of the use of language and speech units in the course of oral and written communication; development of communicative abilities full and consecutive to transfer the thoughts at communication; awakening at them positive motivation to studying Tatar; familiarizing of students' foreigners with spiritual culture of the Tatar people. Thus, the developed textbook of new generation appears as the subsystem caused by the educational purposes and contents which promotes formation at students of the communicative competence necessary for practical use of Tatar.

The system of formation of speech competence of students presented in the textbook consists of several stages. For example, development of the dialogical speech demands the organization of work in the following sequence: acquaintance to a dialogical sample and its reproduction after the announcer; performance of the exercises aimed at selection of a suitable remark from these options; selection of a remark reaction to a remark incentive; drawing up dialogical unity on a sample or the set scheme; expansion of a remark; replacement of these or those remarks; continuation of dialogue on this beginning, etc. As for development of the monological speech, the teacher uses such forms of work as drawing up the coherent statement on the set subject or the offered situation: the description, retelling listened or read, drawing up the story according to the drawing, on a sample, according to the plan, on this beginning, etc. At the same time he pays special attention to training of students to express the relation to a subject of the message and to defend the opinion, logically and consistently to state the thoughts. Grade levels of the monological speech include drawing up the statement at the level of the phrase, the difficult syntactic whole and coherent text. Modeling and realization of the situations stimulating a speech initiative of students for implementation of communication in Tatar leads to practical assimilation of knowledge necessary for satisfaction of the needs for speech communication. At the organization of pedagogical process, it is important to teacher to approach creatively the system of exercises presented in the textbook i.e. to make individual corrections, adapting tasks for certain 
working conditions, simplifying or complicating them. It is not less important to consider the level of practical knowledge of students, to try to make training in language more informative and substantial, to attract additional regional geographic materials. For this purpose it is necessary to be able to choose from variety of the tasks which are contained in the textbook those which are demanded in this concrete situation.

When forming at students of linguistic competence the main attention is paid to development of skills to build the speech in nonnative language according to its lexical and grammatical system, to use standard phrases on the basis of various syntactic models, it is correct to connect them among themselves, to create dialogical and monological statements in compliance with a communication situation. The teacher teaches students to use language material in the concrete act of communication, in dialogical or monological communication, in an oral and written language.

When studying Tatar students seize also sociolinguistic competence. For this purpose in the textbook models of dialogues in which the most common are presented in the Tatar speech grammatical structures, the set expressions necessary for conducting a conversation are given. The teacher can use them in various purposes, for example, for expressive reading dialogue on roles; learning by heart; drawing up dialogue on a similar situation, etc. The manual contains also numerous situational tasks directed to activation at students of skills of the prepared and unprepared dialogical speech.

Discourse competence provides formation at students of ability logically, consistently and convincingly to state the thoughts in Tatar at speech communication. The textbook contains tasks which provide drawing up the story, an arrangement of offers in the logical sequence, inventing of the end or beginning of the offer, etc.

Strategic competence provides formation at students of skills of overcoming certain language and speech difficulties during the receiving or information transfer. As shows experience of teaching Tatar to foreigners, they lack words or grammatical constructions at communication. Therefore we teach students to use verbal and nonverbal means of communication. Taking into account it the textbook included the tasks directed to development of abilities of the use of synonymous forms; addresses to the interlocutor with a request for assistance in the choice of the necessary language forms or words, etc. Ability to use these means helps 2184 the student to continue a conversation and to win against "shortage" of proper words and grammatical constructions at communication. By drawing up dialogical and monological statements students learn to use and nonverbal means of communication (gestures, mimicry, intonation, semantic pauses, etc.) that their speech had live character and was close to the speech of native speakers. The situational tasks connected with everyday life, the solution of certain vital problems, i.e. which are brought closer to conditions of real communication are for this purpose used at lessons.

To development of strategic competence serves models of the numerous dialogues which are contained in the textbook. Learning by heart and reproduction of these dialogues helps to acquire various remarks practically: (question, re-demand, repeated question, consent, disagreement, request, offer, surprise, joy, etc.).

Sociocultural competence provides development of ability to speech communication taking into account national and cultural features of the Tatar people and rules of etiquette. At Tatar lessons students receive data on achievements of the Tatar people and its national peculiarities (the name of national dishes, holidays, etc.). In this regard when developing the textbook texts which give the chance to present and understand national traditions of the Tatar people, as well as models of folklore are included in it (proverbs, sayings, signs, tongue twisters). All this material serves deepening of communicative abilities and increase in interest in national peculiarities of native speakers and, as a result, to dialogue of cultures.

Thus, the various dialogical and monological texts on subject and volume made with use it is most frequency the used lexical units and their grammatical forms, language and speech exercises, situational and communicative tasks, creative approach of the teacher to the organization of educational process act as necessary pedagogical conditions for ensuring practical assimilation of Tatar and formation at foreign students of the main components of communicative competence. For the purpose of the organization of control of communicative abilities of students at the end of each subject of the textbook there is a section "Check Yourself!" in which the situational tasks by all types of speech activity allowing to estimate objectively the level of digestion of language and speech material are presented.

As shows long-term experience, introduction in educational process of manuals of new generation promotes achievement of the following results in 
training in Tatar of foreign students: formation of idea of a role and the importance of Tatar in the polycultural world and bases of respect for other culture; deeper awareness of culture of the people by students of features; communicative competence development of students. Huge role for development of communicative abilities of students and out-of-class actions is plaid by: visit of the Tatar theaters, concerts of the Tatar performers, museums of outstanding persons of the Tatar people, various meetings and youth actions.

\section{Summary}

1.Definition of methodical approaches to foreign students' communicative competence development in Tatar is one of priority linguo-didactic tasks. Speech skills are necessary for them for full language communication in various life situations.

2. Manuals on a communicative basis taking into account innovations in linguo-didactics are developed for training in Tatar of foreign students. The complete methodical system on training in main types of speech activity, as well as development in student's lexicgrammatical skills is presented to them.

3.Manuals of new generation promote formation of idea of a role and the importance of Tatar in the polycultural world and bases of respect for other culture; to deeper awareness of culture of the people by students of features; to communicative competence development of students, i.e. ability and readiness to communicate with native speakers in oral and written forms;

\section{Conclusion}

Only security of educational process with new tutorials to Tatar of foreign students allows achieving the expected results. Optimum organized process of teaching Tatar as foreign trains the identity of the student for adequate perception of other culture, the conscious relation to the existing stereotypes, promotes development of own line of conduct in various situations of cross-cultural contacts. A guarantor of successful work of teachers is the experience of scientific and methodical and educational activity accumulated by them, innovative potential, aspiration to constantly improve the skills, to be aware of all latest techniques in the field of teaching Tatar as foreign.

\section{Acknowledgement}

The research is performed according to the Russian Government Program of Competitive Growth of Kazan Federal University.

\section{References}

[1] Fatkhullova K. S., Yusupova A. Sh., Denmukhametova of E. N. Tatarcha sylshik-Davayte to speak in Tatar - Let's speak Tatar. Kazan: Tat. book of prod.; 2015, p. 311.

[2] Shayakhmetova L. H. Tatar: intensive course. Kazan: Tat. book of prod.; 2012, p. 223.

[3] Fatkhullova K. S., Yusupova A. Sh., Denmukhametova E. N. We talk, we read, we write in Tatar. Kazan: Heter; 2015, p. 184.

[4] Maximov N. V. Technology of training in Tatar on the basis of speech models. Kazan: Tat. book of prod.; 2015; p. 255.

[5] Fahrutdinova R.A. Yarmakeev I.E., Fakhrutdinov R.R. The Formation of Students' Foreign Language Communicative Competence during the Learning Process of the English Language through Interactive Learning Technologies (The Study on the Basis of Kazan Federal University). English Language Teaching; 2014. Vol. 7, No 12, pp. 36-46.

[6] Karabulatova, I.S., Polivara, Z.V., Zamaletdinov, R.R. Ethno-linguistic peculiarities of semantic perception of language competence of Tatar bilingual children. World Applied Sciences Journal; 2013. Vol. 27, pp.141-145.

[7] Yakupov R., Fathullova K., Denmukhametova E. System testing levels of Tatar language proficiency. Journal of Language and Literature; 2016, Vol. 7, No. 1, pp. 223-226.

[8] Nagimov N.I., Tarasova F.K. Designing Foreign Language Lessons Basing on Meta-Subject Approach. Social Sciences; 2015, Vol.10 (4), pp. 407-411.

[9] Kharisov F.F., Kharisova Ch. M. Bilingualism and multi-lingualism in a globalized society. Life Science Journal; 2014. $11 \quad$ (11s), pp. 439-443. http://www.lifesciencesite.com.

[10] Konopatskaya E., Yarmakeev I., Pimenova T. Foreign Language Teaching Strategy for Talented Students in a Small Specialized Institute of a University. The Social Sciences; 2015, Vol. 10 (Issue 9), pp. 2306-2310. 